\title{
Receptor Tyrosine Kinase Inhibitor R1530
}

National Cancer Institute

\section{Source}

National Cancer Institute. Receptor Tyrosine Kinase Inhibitor R1530. NCI Thesaurus.

Code $C 71710$.

A pyrazolobenzodiazepine small molecule with potential antiangiogenesis and antineoplastic activities. Mitosis-angiogenesis inhibitor (MAI) R1530 inhibits multiple receptor tyrosine kinases involved in angiogenesis, such as vascular endothelial growth factor receptor (VEGFR)-1, -2, -3, platelet-derived growth factor receptor (PDGFR) beta, FMS-like tyrosine kinase (Flt)-3, and fibroblast growth factor receptor (FGFR) -1, -2. In addition, this agents exhibits anti-proliferative activity by initiating mitotic arrest and inducing apoptosis. 